Journal of Engineering and Applied Sciences 14 (10): 3144-3149, 2019

ISSN: 1816-949X

(C) Medwell Journals, 2019

\title{
Identification of Brownfield Sites, Classification and Typologies Case Study of Amman, Jordan
}

\author{
Majida Yakhlef and Amal Abed \\ Applied Science Private University, Amman, Jordan
}

\begin{abstract}
Brownfields regeneration in the recent years become an important issue globally for local and regional development, due to its impact on improving the vitality, livability and the quality of life in a city. Jordan is no exception, since, the country have witnessed many economic and demographic changes in the past few decades. Brownfields in Jordan have no clear classification system, strategy, typology and parameters in that regard. Since, terminology of brownfield varies from one country to another this research aims to create a comprehensive brownfield classification by designing a categorization systematic method that is appropriate specifically to the city of Amman context and generally to the whole country. This was conducted by analyzing several variables, original use are size, occupancy level of use and physical condition of facility. Additionally, questionnaire interviews which was carried out with different official authority personal, armed forces, local community and NGO's, wind shield survey. To evaluate the spatial distribution of brownfields in Amman Geographic Information System (GIS) was used. Research findings shows that 154 brownfields sites dispersed over the 20 district of the city. Forming an area about $800,000 \mathrm{~m}^{2}$, most are concentrated in the old districts of the city from small to a medium area size, majority of those sits are abandoned which will make it easier to renovate or regenerate as pockets for different functions from neighborhood shopping center to open spaces parks.
\end{abstract}

Key words: Brownfield, abandoned facility, brownfield classification, vacant property, Geographic Information System (GIS)

\section{INTRODUCTION}

Due to economic flux along with expansion of Amman city associated with changes of city structure and morphology, there are many brownfield sites were formed. Its terminology varies from one country to another based on their policies and strategies. Some defined it as derelict, under-utilized or vacant land that may or may not have real or perceived contamination issues on which previous use has ceased or subsided and the market was not able effectively reuse without some sort of an intervention. While others understand the "brownfield" term as a synonym of previously developed land and may not have to be derelict or abandoned but usually affected by its previous use. Generally, brownfield sites used to contain large number of unused facilities as well as low-quality buildings and utilities which needed to be reused effectively through a comprehensive intervention process, especially it causes decrease in tax income. Examples for these kind of properties are closed factories, former military base, disused warehouses, closed petrol stations, derelict office blocks, discarded railway and many more (Adams, 2004; Alker et al., 2000; Yount, 2003; Oliver et al., 2005; Adams and De Sousa, 2007).
Currently, there is a growing interest worldwide in brownfield issues such as impact, redevelopment, distribution and many more concerns. Therefore, there is a several countries develop strategies and policies for brownfield regeneration despite of redevelopment facing several obstacles such as presence of existing constructions, old utility lines, old foundations andsite contamination (Heberle and Wernstedt, 2006). However, very limited research discussed brownfield classification in Amman context. Tarawneh (2015), presented a classification based on the originating causes that categorize it into three typologies, brownfield caused by deficiency of planning practice by government such as "bits" and "leftover" spaces that resulted from construction/paving streets; brownfield that resulted from unused property land due to challenging topography; brownfield that resulted from human activities such as quarries and mining sites that located within urban context and it needs rehabilitation after materials excavation, prohibited areas that located in unplanned zones and unfinished mega projects and skyscrapers due to construction pause because of economic crisis. This system, unfortunately, focused mainly on the deficiency of planning strategies.

Corresponding Author: Majida Yakhlef, Applied Science Private University, Amman, Jordan 
Generally, Jordan still suffers from lack of systematic, conspicuous strategy discussing definition, typologies and parameters for redevelopment. This may refer to fragmentation regarding responsibility and coordination between stakeholders (Bagaeen, 2006). So, there is a crucial need to define brownfield by typologies that quantify and develop an inventory within local context to provide a knowledge base which may facilitate developing action plan guidelines a long with a national strategy that may transform it from problematic issue to location with potentials and opportunities.

Brownfield classification: Brownfield classification was discussed from several views based on research goals and objectives. Hence, it will be beneficial to understand the classification systems which may help designing a categorization method that fit Amman context. The systems can be summarized as follow.

Brownfield according to the original use of the facility that classify it as follows: industrial, military, railway and transport, agricultural, institutional such as schools, hospitals and prisons, commercial such as shopping centers and offices, cultural such as cultural house, theater and cinema and leisure such as sport ground, parks and open space (Ferber et al., 2006a, b). This classification does not provide any information about status of facilities in terms of current use, physical condition, owner intention regarding redevelopment and rehabilitation feasibility.

Brownfield by economic viability of site highlights how status can change based on variation of location, site treatment cost and other economic conditions. This system developed a model identifies three types of sites, self-developing site with high economic viability and the development project is driven by private funding, potential development site with a borderline of profitability where this project tend to be funded through public-private cooperation or partnership and reserve site where regeneration cannot be profitable, therefore, it relies on public sector or municipality (Ferber et al., 2006a, b). This model mainly focused on development feasibility without considering social, cultural and environmental impact that may have a very important influence on the community. This model is similar to Switzerland Brownfield classification that categorize brownfield into three typologies sites in central urban areas where the value of revitalized land after preparation and transformation is very high which makes them attractive enough for private investors without the intervention of the state, brownfield in the peripheral areas of cities are characterized by lower value of the land, so, contribution of public sector is necessary in order to attract potential investors and locations in rural and urban areas where the value of recycled land is negative which requires substantial financial support from the state, through direct subsidies and tax exemptions (Grimski and Ferber, 2001).

Brownfield by land use classification which was identified by National Land Use Database (NLUD) based on a comprehensive definition of brownfield terminology. It includes the following categories, previously developed gray-field which is mainly related to former commercial properties and are not contaminated but that are may be under-utilized, derelict or vacant, derelict/abandoned lands and buildings related to damaged properties by previous activities, especially most of them have contamination. Therefore, it needs a serious intervention but unfortunately their owner, mostly private have no intention to reopen or invest, vacant buildings/lands related to property that may be empty or unoccupied and its owner is not taking reasonable steps to maintain it. Therefore, it can be considered as unsecure environment despite its owner express interest with property, partially occupied building/lands can be referred to partially vacant land which is usually large enough but may not be capable for further development without intervention due to significant physical, environmental or infrastructural limits to development such as steep topography, on-site wetlands, floodplains or significant riparian areas and infrastructure constraints. These lands can be categorized in three categories, not currently fully in use, land or building currently in use and allocated by different land use in local plan and land or building currently in use with redevelopment potentials (Parker et al, 2009). This system mainly tried to connect potentials of investment with current physical status in terms of land use and level of contamination along with owner intention.

This research aimed to introduce a more comprehensive classification of brownfield in Amman context. It considers several variables that include original use, size, level of occupancy and physical condition.

\section{MATERIALS AND METHODS}

Brownfield classification is an important step that helps in identifying, describing and mapping the issue clearly. Hoping such classification offers support for decision makers to identify brownfield that worth to be redeveloped. Especially, that basic data about brownfield sites in Amman is not available at all because of potential fear of the negative stigma on property value along the inability of community to recognize purpose of such classification. Thus, the research data based on documents and information gained through observational 
survey along with snowball sampling technique that started by informal conversation and then developed to be semi-structured interviews with employees in Greater Amman Municipalities (GAM), local authorities that responsible for individual district, Jordan Armed Forces that responsible for military sites, Jordan Hijaz Railway that responsible for several stations and bridges/tunnels, Ministry of Industry and Trade that responsible for industrial and commercial locations and Non-Governmental Organizations (NGOs) along with local community may provide data or documents related to such sites.

"Brownfield" terminology were investigated through the following variables; original use related to the original use of the facility that include, industrial, commercial, residential, transportation and others; size measured by area size of land property with facility which categorized to five levels, $<1$ donum $\left(1,000 \mathrm{~m}^{2}\right),(1-5)$ donum, (5-10) donum, (10-20) donum and more than (20) donum; occupancy defined through level of facility usage that ranging from abandoned, partially used to fully used with same or different function, physical condition related to the quality of building's structure that ranging from totally damaged (Bad), deteriorated/partially damaged (Fair), tolerable structure maintained facility (Good). The above variables presented in a table based on Amman's administrative districts. Then delineate the spatial distribution of brownfield in all districts of Amman using Geographic Information System (GIS). This helped to understand the agglomeration of brownfield and determine its proportion at both district and city level to suggest strategies and policies for redeveloping it to promote a more sustainable city and improve quality of life to its residents.

Data collection: A team of 8 qualified research assistants were divide into groups of two to cover the 20 districts of the city in a time period from January 8th to May 23rd 2018 to gather factual information and locating brownfield sites. Part of the survey was used in a quantitative way to give a solid and alleviate findings that can form a rep of reasonable and justifiable image of reality. Documentation regarding brownfield facilities were gathered from designated authorities such as GAM, department of land and area, royal geographic center and Amman District zones. The second part was more towards a qualitative approach that filled the missing information, this was conducted by car windshield survey, observational mapping, photography and by using snowball sampling technique, face-t-face interviews was chosen to conduct the interviews, since, Jordanian are not familiar to surveys of any kind, face-to-face started by informal conversation and then developed to a structured to semi-structured interviews to collect information about brownfields location, original use, area size, level of use occupancy and physical condition, interviews with officials, local authorities employees from Greater Amman Municipalities (GAM) (28) respondent Jordan Armed Forces and Jordan Hijaz Railway personal where interviewed, from the Ministry of Industry, people from Non-Governmental Organizations (NGOs), land lords, 180 residents representing all walks of life were randomly selected.

\section{RESULTS AND DISCUSSION}

The research outcome presented an assessment of brownfield in Amman city. The collected data shows that there are (154) brownfield sites dispersed over (20) districts. It forms about $800,000 \mathrm{~m}^{2}$, most of it are abandoned and were used as commercial or residential facility with area ranging from $1000-5,000 \mathrm{~m}^{2}$. Brownfields were assessed in terms of four variables.

Original use: Research data shows that the most common use is residential and then commercial that form (48 out of 154, 40 out of 154), respectively. However, the military is the least that forms (4 out 154). As shown in Fig. 1-5, (32 out of 154) sites used to have an industrial use. These facilities mainly agglomerated in Al-Qwesmih with ( 8 out of 32 ). This may refer to the municipality zoning where most of land use of this district is industrial. Moreover, the following districts have equal number of industrial brownfields; Tareq, Al-Abdali, Tla Al-Ali and Shafa Badran Districts where each has 4 facilities.

For the commercial use, Al-Abdali District has the highest number of commercial brownfield facilities that form (8 out 40) as shown in Fig. 5. This may refer to

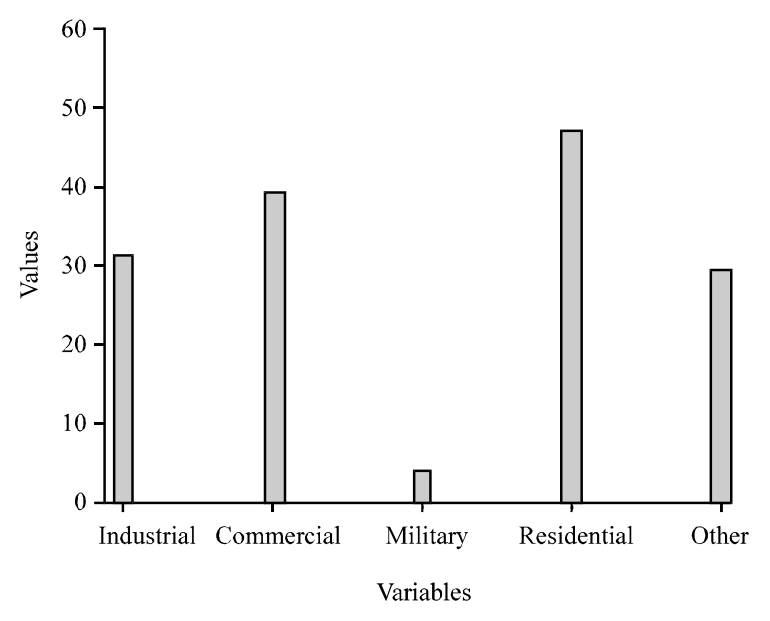

Fig. 1: Brownfields according to original use 


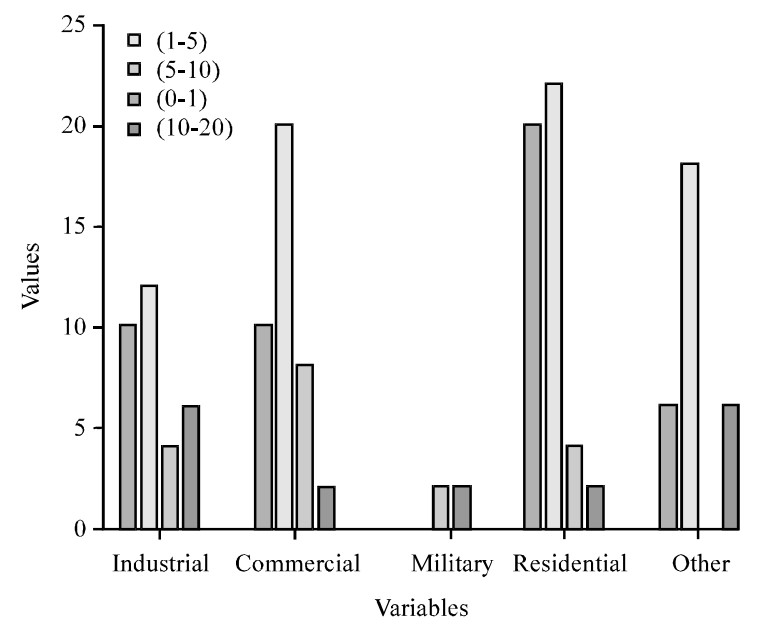

Fig. 2: Size distribution of brownfield

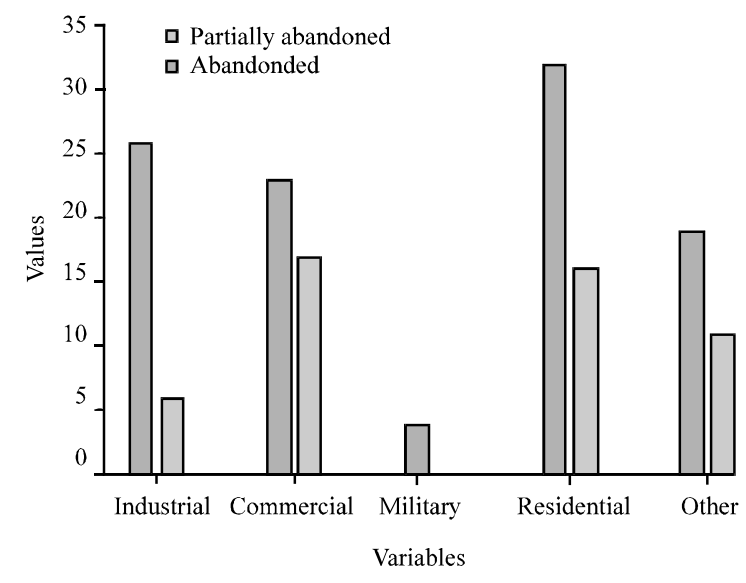

Fig. 3: Current occupancy of brownfield

development plan of this district that target high-income class by including department's stores, fancy cafes and restaurants which lead to gentrification of indigenous business who cannot handle the financial pressure of rental cost and property tax. Moreover, both Sweileh and Marka has similar number of brownfield ( 6 out of 40) as a result for poor economic plan that makes several corporate go through bankruptcy. On the other hand, the least brownfields were found in Ras-Alaen "the historic center or old downtown Amman". This can be considered as an indication of its significance as a financial and economic aspect despite the attempt to replace it with the Alabdali.

Brownfield of residential use has the highest frequency that formed (48 out of 154). It is agglomerated in the oldest city center such as Zahran, Wadi Al-seir, Shafa Badran and Al-Jubiha with $(14,8,8,6)$, respectively. These districts resided by middle to high income individuals but the indigenous residents started leaving

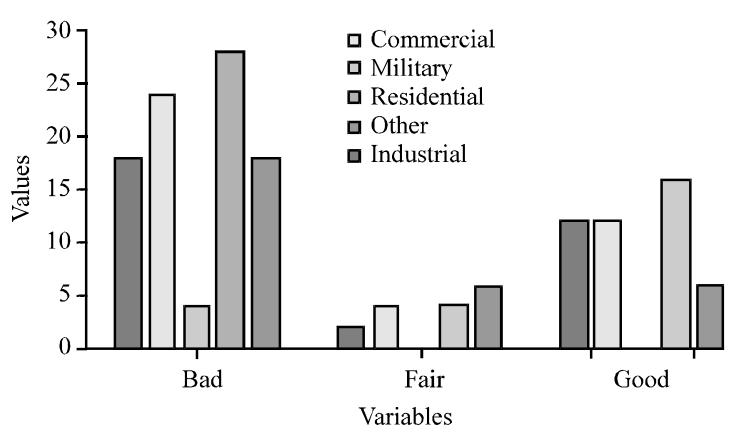

Fig. 4: Physical condition of brownfield

these districts when Iraqi refugees moved to it in 1990s during Iraqi war. However, many new districts have none brownfield such as Tlaa Al-Ali, Bader, Al-Yarmouk, Sweileh, Abu Nuseir, Marka, Tareq and many more.

The least score of brownfield use is the military facilities, since, it considered confidential and many constrains of obtaining information. Only 4 sites were used as training camps for army recruitment service to youth before peace treaty took place in 80 s. Finally, the last type of this variable was other which included gas stations, parking lots, scrap yards and unidentified facilities formed (30 out of 154) was scattered over the city. Where the following districts has the highest brownfield are Zahran, Sweileh, Al-Yarmouk and Al-Qwesmih that has $(6,4,4,4)$, respectively.

Size: Was evaluated through area of brownfield sites. As shown in Fig. 2, most of brownfield facilities ranging from small to moderate size where the area ranging between $1,000-5,000 \mathrm{~m}^{2}$ forms about a half of each brownfield category based on the original sample. Also, the area $<1,000 \mathrm{~m}^{2}$ form about $30 \%$ of the sample. This may relate to the small size of lot based on zoning plan of municipality. This can be ensured that the facilities which is larger than $10,000 \mathrm{~m}^{2}$ not exceed $5 \%$. This means that the brownfield site can be considered as pockets within urban context have a potential for positive effect to improve life quality for surroundings. Moreover, the small to medium size may encourage private and public sector to invest, since, it will provide a chance to test the feasibility of brownfield regeneration at small scale.

Level of occupancy: Brownfield sites were assessed through three levels of occupancy that categorized as follow; Abandoned (A), Partially abandoned (P) and Fully used (F). As shown in Fig. 3, unfortunately, about $80 \%$ of the brownfield facilities are abandoned while none is fully used. Industrial facilities have the highest score of abandoned facilities that formed ( 28 out of 32 ) which is 


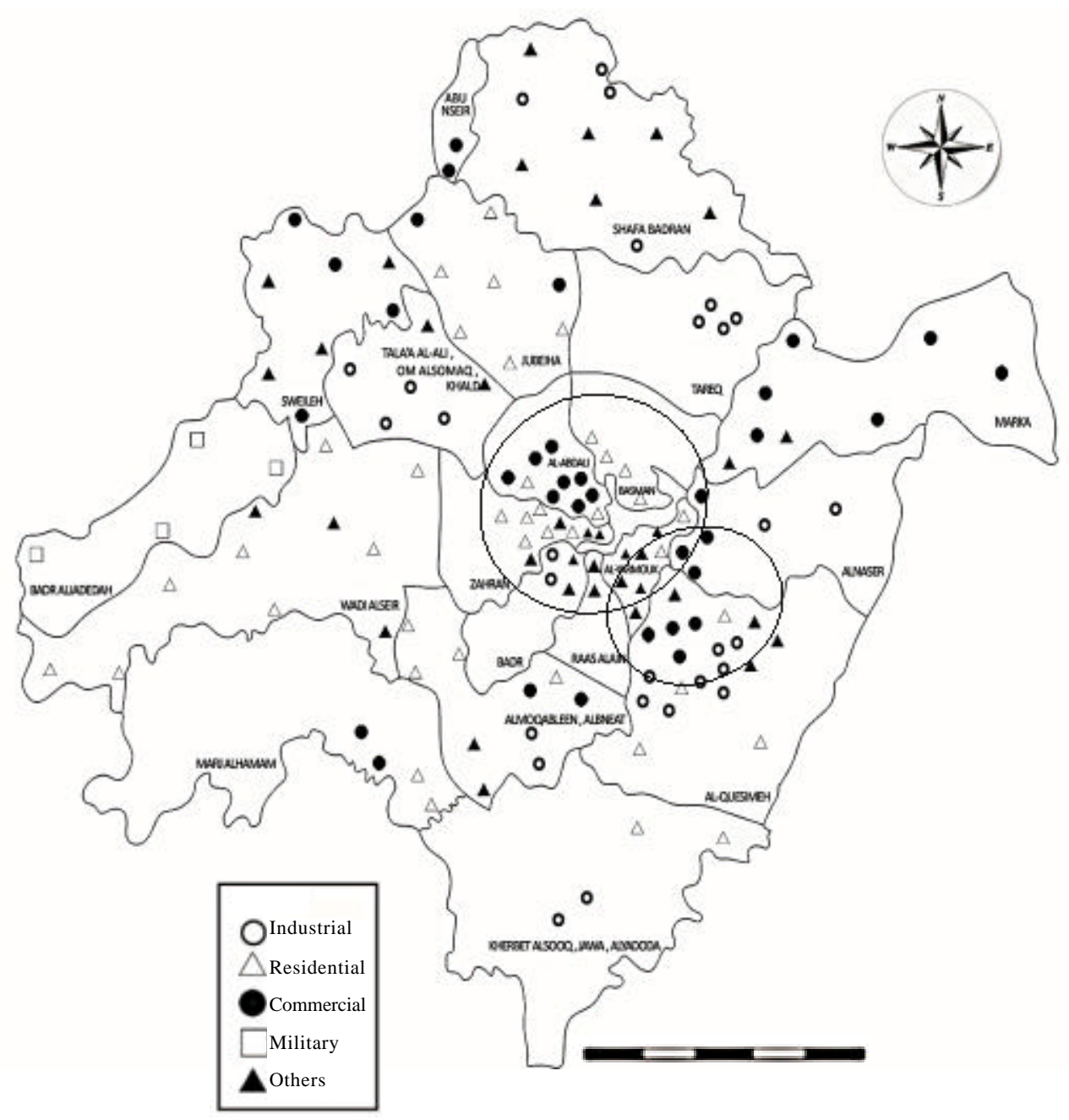

Fig. 5: Spatial distribution of brownfield in Amman

about $88 \%$ while the commercial facilities have the lowest score ( 24 out of 40 ) which is $60 \%$. This can be explained that the commercial facilities are more convenient to be used partially for neighborhood services and small business. As same as some abandoned residential properties that occupied by refugees and Foreign workers despite of poor living conditions that represented by lack of utilities along with deteriorated structure. On the other hand, the "other" uses of brownfield facilities mainly closed down, especially gas stations, however, section of its yard reused as car wash, flee market and livestock market. Finally, all military sites are abandoned due to abolition of compulsory conscription in the country.

Physical condition: Facilities of brownfield were evaluated through the quality of building's structure. Three levels of assessment were classified as follow:
Good $(\mathrm{G})$ that can be reused as it is Fair (F) means need minor maintenance and Bad (B) needs a major rehabilitation/remodeling or demolition. As shown in Fig. 4, most of brownfields are in a bad deteriorated condition that formed about $54 \%$ which is about the same for industrial, commercial, residential and other uses that formed $(56,60,58$ and $60 \%)$, respectively. Therefore, there is a serious need to have a guide for regeneration/redevelopment plan that will reverse the negative effect of those facilities on surroundings. Such strategy can participate in boosting stagnant economy by creating jobs, especially in districts with high rate of unemployment or can improve the environment quality in areas suffering from the deficiency of green/open space by reusing it to be a green zone or city park. Generally, it can be redeveloped based on community's need. 


\section{CONCLUSION}

Based on the findings of this research conclusions may be summarized as follows: brownfield issues in Amman context is one of the crucial problems that the city suffering from. Especially, most of its facilities are in a bad deteriorated conditions that affect negatively socially, economically and on the on surroundings. As results show that brownfield concentrated or close to the old districts such as Zahran, Al-Quieswemieh, Sweileh, Wadi Al-Seir and Al-Abdali with mainly residential and commercial original uses ranging from small to medium size in terms of area which makes their regeneration easier and shorter in time than large ones (Lange and McNeil, 2004), this is consider a valuable finding to authorities and people in legislation to prioritize their planning strategies, since, this issue is getting more serious and Amman's municipality has no clear definition, classification, parameters or even vision for regeneration such sites. Therefore, it is highly recommended to have a comprehensive strategy solving this problematic issue at several levels to benefit the community physically, socially, economically, environmentally and culturally.

\section{RECOMMENDATIONS}

Additional recommendations may have a positive influence on brownfield in Amman context are encouraging scholars to study brownfield phenomena in Jordan as a step for providing a guide to manage this issue. Moreover, activate channels between them to avoid duplicating work and filling the gap with a comprehensive vision. Realizing the necessity of redeveloping brownfield across different districts in order to improve life quality based on community's need. This can be achieved through citizen, land lords and investor's participation. As brownfield terminology is not known or used by officials, the public it's very important to hold an awareness discussions, public meetings to educate them about the negativity of such site and positivity of its regeneration and redevelopment.

Developing and amending of Jordanian planning standards to include brownfield issue along with law enforcement to eliminate the spread of it over Amman city. Accordingly, this research can be considered as a starting point for a chain of integrated investigation in theory, research and implementation that could be translated to sufficient policies.

\section{ACKNOWLEDGEMENT}

The researchers are grateful to the Applied Science Private University, Amman, Jordan for the full financial support granted for this research project.

\section{REFERENCES}

Adams, D. and C. De Sousa, 2007. Brownfield development: A comparison of North American and British approaches. Proceedings of the 10th European Conference on Urban Research Association, September 12-14, 2007, University of Glasgow, Glasgow, Scotland, UK., pp: 1-27.

Adams, D., 2004. The changing regulatory environment for speculative housebuilding and the construction of core competencies for brownfleld development. Environ. Plann. A. Economy Space, 36: 601-624.

Alker, S., V. Joy, P. Roberts and N. Smith, 2000. The definition of brownfield. J. Environ. Plann. Manage., 43: 49-69.

Bagaeen, S.G., 2006. Brownfield sites as building blocks for sustainable urban environments: A view on international experience in redeveloping former military sites. Urban Design Intl., 11: 117-128.

Ferber, U., D. Grimski, K. Millar and P. Nathanail, $2006 \mathrm{a}$. Sustainable brownfield regeneration: CABERNET network report. Master Thesis, University of Nottingham, Nottingham, England.

Ferber, U., P. Stadt, E. Leipzig, P. Nathanail and J.B. Jackson et al., 2006b. Brownfields Handbook. Leonardo da Vinci Project Inc., New York, USA., .

Grimski, D. and U. Ferber, 2001. Urban brownfields in Europe. Land Contam. Reclam., 9: 143-148.

Heberle, L. and K. Wernstedt, 2006. Understanding brownfields regeneration in the US. Local Environ., 11: 479-497.

Lange, D.A. and S. McNeil, 2004. Brownfield development: Tools for stewardship. J. Urban Plann. Dev., 130: 109-116.

Oliver, L., U. Ferber, D. Grimski, K. Millar and P. Nathanail, 2005. The scale and nature of European brownfield. Proceedings of the CABERNET 2005 International Conference on Managing Urban Land LQM Ltd, April 13-15, 2005, Nottingham, UK, Belfast, Northern Ireland, UK., pp: 1-9.

Parker, R., L. Juntunen, B. Goodman and K. Coddington, 2009. Sandy urbanisation study. Master Thesis, ECONorthwest, Sandy, Utah.

Tarawneh, D., 2015. Brownfield landscapes of Amman: Defining typologies of unnamed terrains. Proceedings of the International Conference on Transformation of the Urban Character of Arab Cities Since the Late Last Century, April 22-24, 2015 , German-Jordanian University, Amman, Jordan, pp: 90-98.

Yount, K.R., 2003. What are brownfields? Finding a conceptual definition. Environ. Pract., 5: 25-33. 